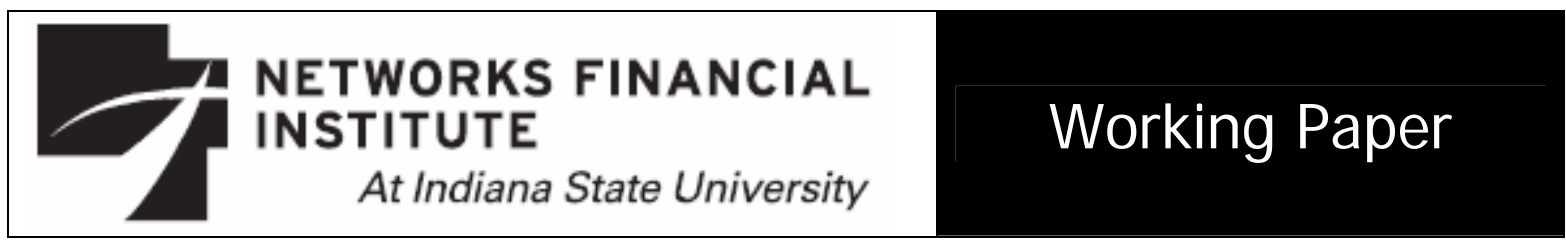

2007-WP-02

January 2007

\title{
Are Financial Education Programs Meeting the Needs of Financially Disadvantaged Consumers?
}

\section{Yunhee Chang and Angela Lyons}

Abstract: This paper uses data collected from a retrospective pre-test to investigate the impact that a financial education program has on participants' financial behaviors. Specifically, we compare program impact across participants with varying levels of financial competency prior to the program and examine whether the program is meeting the educational needs of those it was designed to target - namely, financially disadvantaged consumers. The findings show that the program benefited all of the participants and the greatest improvement in financial behavior was observed for those who reported lower levels of financial ability prior to the program. The findings offer important practical information to consumer educators, program developers, and financial counselors.

\section{About the Authors:}

Yunhee Chang is a Visiting Assistant Professor at University of Mississippi.

Angela Lyons is an Assistant Professor at University of Illinois at Urbana-Champaign.

Keywords: financial education, behavior change, disadvantaged consumers

The views expressed are those of the individual author and do not necessarily reflect official positions of Networks Financial Institute. Please address questions regarding content to Yunhee Chang at chang@olemiss.edu. Any errors or omissions are the responsibility of the author.

NFI working papers and other publications are available on NFI's website (www.networksfinancialinstitute.org). Click "Research" and then "Publications/Papers." 


\section{Are Financial Education Programs Meeting the Needs of Financially Disadvantaged Consumers?*}

\section{Yunhee Chang and Angela Lyons}

\section{Introduction}

In recent decades, debt-to-income ratios and insolvency rates for lower-income households in the U.S. have grown dramatically (Bird, Hagstrom, \& Wild, 1999; Lyons, Chang, \& Scherpf, 2007). Consumers who are socially and financially disadvantaged are increasingly demanding consumer finance education that is specifically targeted to address their financial needs and overall financial situation. However, many conventional consumer finance curricula have primarily been developed to assist middle-class, white-collar workers with retirement planning and are not equally as beneficial to lower-income audiences with limited financial resources and experience. This study examines the impact of a financial education program that was specifically designed for lower-income consumers and investigates whether the program has effectively served those individuals with more limited financial competency.

Many studies have attempted to identify common financial problems that consumers with limited financial resources and experience face and determine what kinds of financial education they need (Jariah, Husniyah, Laily, \& Britt, 2004; Joo, 2002; Xiao, Newman, Prochaska, Leon, \& Bassett, 2004). Several studies have discussed how financial education programs can enhance financial literacy and lead to positive behavior change for financially disadvantaged individuals (Anderson, Zhan, \& Scott, 2004; Block-Lieb, Baron-Donovan, Gross, \& Wiener, 2004;

\footnotetext{
* Acknowledgements: The authors graciously acknowledge assistance from the University of Illinois Extension Consumer and Family Economics Team. Specifically, we thank Debra Bartman, Ellen Burton, Karen Chan, Mary Ann Fugate, Patricia Hildebrand, Jennifer Hunt, Linda Crawl Jackson, Evelyn Prasse, Kathy Reuter, Lois Smith, Kathy Sweedler, and Susan Taylor. All views expressed in this paper are those of the authors and do not reflect the views or policies of University of Illinois Extension or any members of its staff.
} 
Braunstein \& Welch, 2002; Lyons, 2005; Lyons, Chang, \& Scherpf, 2007; Lyons \& Scherpf, 2004; Lyons, Palmer, Jayaratne, and Scherpf, 2006; Marlowe, Godwin, \& Maddux, 1996). However, these studies have not critically examined the extent to which the programs are helping to improve the financial literacy of those who need it the most. Moreover, it is difficult to assess whether those who need financial education the most are actually benefiting more from the program than those who already demonstrate a moderate level of financial competency.

One way to assess whether a financial education curriculum properly corresponds to the needs of its target population is to compare the program's impact across participants with varying levels of financial competency prior to the program. In the literature, little is known about how program effectiveness is related to participants' competency levels. It is critical to the success of any program that it serve the needs of the participants it was designed to primarily target. Thus, it is essential that consumer finance curricula, which are designed to meet the financial needs of financially disadvantaged consumers, actually match participants' levels of financial competency.

This study uses data collected from participants of a financial education program that was designed to target low-income adults. Using this data, we examine how participants' prior levels of financial ability are correlated with how much they learn as a result of participating in the program. We argue that if a participant's prior level of financial ability is negatively associated with the magnitude of learning, then the program is properly designed and is effectively reaching its target population, which in this case is financially disadvantaged consumers.

The results from this study provide evidence that the program in question is of greater benefit to those who report lower levels of financial ability prior to the program. Thus, the program has likely been successful in targeting those who need financial education the most. 
Furthermore, the curriculum materials are likely to be well-matched to the financial abilities of the program participants. This study offers important practical information to consumer educators, program developers, and financial counselors. Also, it adds to the broader literature of economic and financial education and provides insights into how participants’ prior knowledge levels can affect teaching effectiveness. The methodology used in this paper can be applied to examine the effectiveness of other types of education programs.

\section{Review of Literature}

Despite the importance of targeted financial education for low-income consumers, most institutions and agencies that offer such programs do not have adequate financial and human resources to collect data and conduct careful evaluations (Anderson, Zhan, \& Scott, 2004; Lyons, 2005; Lyons, Chang, \& Scherpf, 2007; Lyons, Palmer, Jayaratne, \& Scherpf, 2006). Numerous studies in the education literature indicate that students' prior level of subject knowledge is positively associated with better performance in school (Casanova, Garcia-Linares, de la Torre, \& Carpio, 2005; Petrides, Chamoro-Premuzic, Frederickson, \& Furnham, 2005; Zietz \& Joshi, 2005), which may apply to the case of adult consumer education. However, the findings from these education studies only suggest that students who enter programs with greater prior knowledge are more likely to demonstrate higher performance by the end of the program. The findings do not necessarily mean that better-prepared students experience greater overall improvement. For example, it could be the case that high-performing students prior to the program are still high-performing students at the end of the program. However, they may not improve by as much as low-performing students, even though the low-performing students may still be at a lower level than the high-performing students at the end of the program. Thus, 
higher post-program outcomes might simply reflect initial gaps in knowledge and not larger improvement gains for those students with greater knowledge prior to the program.

Evidence from the financial education literature is quite the opposite. A recent study by Lyons, Chang, and Scherpf (2007) assessed the impact of a financial education curriculum and found that program participants were more likely to improve their consumer behaviors if their initial behavior levels were relatively low. However, they used prior behavior levels as control variables in the regression model, and they did not identify whether the inverse relationship between the prior level and the probability of improvement was due to the varying effect of instruction or whether it was simply an artifact of the data. It is possible that the inverse relationship found in their study was merely reflecting the fact that those who had lower prior levels of behavior at the onset of the program also had greater room to improve throughout the course of the program. A more accurate understanding of how these programs change the behaviors of consumers with varying levels of prior knowledge and experiences should take into consideration how initial levels of knowledge and experience affect the "slope," and not just the “intercept," of the treatment effect.

The expected relationship between the program effect and a participant's prior level of knowledge or behavior can be ambiguous. On the one hand, participants who start out with higher initial levels may learn less, because the new information may be repetitive given their prior level of knowledge or behavior. On the other hand, their prior level of knowledge or behavior may facilitate learning due to a learning curve effect, in which case the better-prepared participants are able to gain more from the program. Prior knowledge in a specific subject area such as personal finance may have a positive impact not only on post-program outcomes but also on the magnitude of pre-post differentials. 
It has been shown in the general economic education literature that students' initial knowledge of a subject is an important predictor of how much they learn from the instruction (Meyer \& Shanahan, 1999 and 2001; Shanahan \& Meyer, 2003). Targeted teaching methods that respond to individual variation in prior knowledge of the subject may improve the program's overall impact (Meyer \& Shanahan, 2001). Also, if limited learning results from participants with lower levels of financial competency prior to the program, a better-targeted program design or variation in instruction methods may need to be devised. A well-targeted financial education curriculum for financially-disadvantaged consumers would ensure that the program benefits participants with lower levels of skill prior to the program, at least as much as those with relatively higher levels of skill.

This study uses five financial behavior questions to construct a financial ability scale based on a participant's behaviors prior to and following the program. The program outcome is modeled as a function of treatment (measured by the number of modules completed) interacted with prior level of financial ability. In an attempt to deal with potential bias arising from nonrandom assignment to treatment, other participant characteristics are held constant in addition to the number of modules and prior levels of behavior.

\section{Data}

The data for this study were collected from participants of the financial education program All My Money, a nationally-recognized program designed to teach low-income consumers basic financial skills. The curriculum was developed as a train-the-trainer program by University of Illinois Extension educators in 1997. Since that time, it has been taught to the staff of non-profit organizations, government agencies, and other social service agencies and community groups. The trained staff subsequently redelivers the program to low-income clients 
with limited financial ability. The curriculum consists of eight modules that include: 1) making spending choices, 2) envelope budgeting, 3) planning expenditures, 4) understanding credit; 5) handling credit problems, 6) building consumer skills, 7) taking consumer action, and 8) managing a checking account. Each module consists of hands-on activities and handouts as well as lesson plans and instruction guides.

The program is typically delivered over the span of a few days or a few weeks depending on how many modules are taught. Each module takes approximately 60 minutes to deliver, and the number and types of modules offered to participants vary significantly by instructor and location. Most participants, however, are taught the budgeting, planning, and credit lessons while the banking and problem-handling modules are taught less frequently.

Since its inception, the program has primarily been offered in the state of Illinois and has targeted low-income audiences from a wide range of agencies and organizations including welfare-to-work and other social service groups, non-profit organizations, community and faithbased organizations, and financial institutions. We used a retrospective pre-test (RPT) to collect evaluation data from program participants in Illinois. The RPT was administered in the same way as a post-test in that participants were asked to answer questions about their level of financial ability after the program. They were then asked to think back to their level of financial ability prior to the program and report how these levels had changed as a result of their participation in the program.

There are potential limitations associated with using RPTs (i.e., learning effects can occur and biases may result from self-reporting and recall errors) (Lamb, 2005; Lamb \& Tschillard, 2005; Lyons, Chang, \& Scherpf, 2007). However, even with its limitations, an RPT is considered an acceptable method for evaluating program impact, especially for programs that 
target limited resource audiences (Lamb \& Tschillard, 2005). Since it only has to be administered once, an RPT can be an efficient means for collecting impact data from low-income clients with low response rates, high attrition rates, and limited human and financial resources (Lyons, Chang, \& Scherpf 2006). It also can reduce response-shift biases that result when a participant's frame of reference changes significantly during the program (Lamb, 2005; Lamb \& Tschillard, 2005; Lyons, Chang, \& Scherpf 2007). For example, prior to the program, participants may think they understand the difference between fixed and variable expenses or how to create a budget; but at the end of the program, they may realize that they really did not understand these consumer finance concepts.

For the purposes of this study, participants were asked to complete an RPT at the end of the program. Specifically, they were asked to conduct a retrospective self-assessment with respect to the following five behavior categories: budgeting, intra-household communication, bill payment, ability to handle consumer problems, and comparison shopping. Participants indicated on a 4-point Likert scale how often they engaged in each financial behavior prior to the program and how often they planned to engage in each financial behavior now that the program was completed. Responses ranged from almost never to almost always, where " 1 ” was equal to almost never, "2" was equal to sometimes, "3" was equal to often, and "4" was equal to almost always. Higher values, therefore, denoted higher levels of financial ability. ${ }^{\dagger}$

We used participants' responses to these five questions to construct a financial ability scale based on participants' behavior prior to and following the program. Specifically, we added

\footnotetext{
${ }^{\dagger}$ The specific behavior items included (1) do not run out of money, (2) talk with family about money, (3) do not pay bills late, (4) complain when having a consumer problem, and (5) compare prices and quality before buying. These items are similar to those included in the Financial Fitness Quiz developed by O'Neill and Xiao (2003). Although the inter-item reliability coefficient estimated by Cronbach's Alpha shows that the five questions appear to measure quite different concepts from one another, it is argued that the scale meets conceptual validity to measure overall consumer financial effectiveness. The reliability statistics of this scale are available upon request. Since the survey was conducted as a one-shot questionnaire, the test-retest reliability cannot be assessed.
} 
up a participant's responses for the five behaviors and divided by five to obtain an average level of financial ability for each program participant. Thus, two measures of overall financial ability were constructed - Average Prior Level and Average Post Level. The first measure (Average Prior Level) represents participants’ average financial ability prior to the program and the latter measure (Average Post Level) represents participants’ average financial ability after completing the program. Some demographic and income information also was gathered (e.g., age, gender, education, family size and composition, and personal and household income) in addition to the number of modules completed and the program location.

Between 1998 and 2002, 763 evaluations were collected. Of these, 602 surveys were considered complete and 161 had to be dropped due to incomplete or missing information. The final sample consisted of 435 agency staff (72\%), who were trained as future instructors of the program, and 167 low-income clients (28\%), who were taught by the agency staff. ${ }^{\ddagger}$

Table 1 presents the descriptive statistics for the sample. An average participant tended to be a 39-year-old female with some college education. In general, participants ranged from those in their early twenties to those nearing retirement age. Over $87 \%$ of the respondents were female and only $13 \%$ were male. In addition, $70 \%$ of the sample lived with at least one other adult in the household. With respect to income, the majority of respondents (53\%) reported that they earned less than $\$ 1,500$ a month, although nearly half (45\%) reported other income sources in the household (typically spousal earnings or transfer payments). Since Chicago is the largest metropolitan area in the state, it should not be surprising that most of the programs were delivered in the Chicago area (61\%). Out of the eight curriculum modules, participants completed on average 6.7 modules.

\footnotetext{
${ }^{\ddagger}$ Careful analysis of both quantitative and qualitative data revealed that participants’ prior levels of financial ability were similar for both the agency staff and the clients on average. In fact, a number of agents indicated that they were struggling financially themselves.
} 
With respect to the two measures of financial ability (Average Prior Level and Average Post Level), the data show that, as a result of the program, participants' average financial ability improved from 1.83 points to 3.29 points. As an explorative attempt, we tested whether differences in pre and post levels of financial ability were statistically significant, and looked at these differentials by quartiles that were based on participants' prior levels of ability (see Table 2). For all quartiles, the pre-post differentials indicate statistically significant improvements $(\mathrm{p}<$ 0.01). Table 2 is consistent with the literature and shows that participants in the higher quartiles, who reported higher levels of prior ability, also reported higher levels of ability following the program. For example, average financial ability following the program was 3.15 points for participants in the $1^{\text {st }}$ quartile and 3.49 points for those in the $4^{\text {th }}$ quartile. Interestingly, the magnitudes of the pre-post differentials were larger for participants in the lower quartiles, who reported lower prior levels of ability, than for those in the higher quartiles, who reported higher prior levels of ability. This descriptive finding suggests that participants who initially had poor financial management skills experienced larger improvement gains than those who had relatively better skills. However, these differentials do not take into account the amount of financial education the participants received during the program, which we measure by the number of modules they completed. In order to assess how program impact varies by the prior level, a measure of treatment is needed.

\section{Methods}

Ideally, assessment of the program's impact requires experiment-type data, which contain pre and post responses from both treatment and control groups. In the absence of observations from non-participants, this study uses variations within the participant sample in the number of modules taught as a proxy for treatment. That is, instead of comparing participants with non- 
participants, we compare participants who took more modules against those who took fewer modules. In this particular program, the number of modules each individual takes is usually not determined by the participant but rather by the program provider. This minimizes the bias arising from self-selection and attrition problems. In addition to serving as the treatment variable in the absence of a non-participant placebo group, the number of modules (e.g., the length of the program) also has important implications for curriculum design (Lyons, Chang, \& Scherpf, 2007).

In our model, we examine the factors that determine a participant's level of financial ability at the end of the program. The dependent variable is PostLevel, which represents a participant's self-reported level of financial ability after the program. PostLevel is defined as both a continuous and discrete choice variable. Specifically, we estimate one model using a participant's average financial ability after completing the program, where PostLevel is set equal to Average Post Level. Recall that Average Post Level was the participant’s post level of financial ability averaged over the five financial behaviors. In this case, PostLevel is a continuous variable ranging from 1 to 4 .

We then estimate a series of models using the participant's ranking of their financial ability at the end of the program for each of the five financial behaviors (i.e., 'do not run out of money,' 'talk about money with family,' 'pay bills on time,' 'complain when having consumer problems,' and 'compare price and quality before buying'). For these models, PostLevel is a discrete choice variable that is equal to $1,2,3$, or 4 . Recall that these were the values assigned to the 4-point Likert scale, where " 1 ” was equal to almost never and " 4 ” was equal to almost always, and higher values represented higher levels of ability for each behavior.

In the most simplistic terms, we can express our model using the following equation: 


$$
\text { PostLevel }=f(\text { Modules, } \text { PriorLevel, } \boldsymbol{X}) \text {. }
$$

According to the model, PostLevel is a function of the variable Modules, which represents the number of modules completed by each participant, ranging from 1 to 8 . It also is a function of PriorLevel, which simply denotes the participant's level of financial ability prior to the program. $\boldsymbol{X}$ is a vector of participant characteristics including: age, gender, years of schooling, household size, whether the household has another adult member, personal monthly income of participant, other sources of income for the household, program location, and whether participant is a staff member or client. It is important to note that the assignment of participants to varying amounts of instruction (e.g., number of modules completed) may not have been random and hence the number of modules completed might be correlated with a participant's prior ability level as well as with other participant characteristics. By holding PriorLevel and the participant characteristics constant, the bias that might be introduced by endogenous treatment can be minimized. ${ }^{\S}$

It is hypothesized that the effect of additional modules on a participant's post-level of behavior varies by the participant's initial level of behavior. For this reason, we model the regression equation for the $i^{\text {th }}$ participant as follows:

$$
\text { PostLevel }_{i}=\text { BModules }_{i}+\gamma \text { PriorLevel }_{i}+\text { _Modules }_{i} \text { PriorLevel }_{i}+\boldsymbol{X}_{i} \boldsymbol{\delta}+\varepsilon_{i},
$$

where $i=1,2, \ldots n$ and $\varepsilon \sim i i d N\left(0, \sigma^{2}\right)$. The model is estimated using Ordinary Least Squares

\footnotetext{
$\S$ Table A1 in the Appendix shows that, when demographic variables are held constant, there is no statistically significant relationship between an individual's prior level of financial ability and the number of modules completed. This finding suggests that assignment to various degrees of treatment is likely to be independent of prior level of ability.
} 
(OLS). ${ }^{* *}$ The coefficient of key interest is the one assigned to the interaction term, $\lambda$, which captures how the treatment effect varies by the prior level of financial ability for each individual. The literature, which has shown that financial education positively impacts consumers' behavior, predicts that $\boldsymbol{\beta}$ will be positive (Anderson, Zhan, \& Scott, 2004; Block-Lieb, Baron-Donovan, Gross, \& Wiener, 2004; Braunstein \& Welch, 2002; Lyons, Chang, \& Scherpf, 2007; Marlowe, Godwin, \& Maddux, 1996). Additional research, which shows that participants' prior levels of behavior are positively correlated with their post levels of behavior, predicts that $\gamma$ will also be positive (Casanova, Garcia-Linares, de la Torre, \& Carpio, 2005; Petrides, Chamoro-Premuzic, Frederickson, \& Furnham, 2005; Zietz \& Joshi, 2005). A negative $\lambda$ suggests that the program impact may be inversely related to an individual's prior level, signifying that participants with lower prior levels gain more from the program than those with higher prior levels. Assuming the program results in positive gains in financial ability, we can think about three potential scenarios for how the program impact might vary by prior level of ability $(\lambda>0, \lambda=0$, and $\lambda<0)$.

The three scenarios are illustrated in Figure 1. In each figure, we divide participants into four quartiles based on their average level of financial ability prior to the program (Average Prior Level). Participants in the $1^{\text {st }}$ quartile are classified as having 'Low Prior Level' and those in the $4^{\text {th }}$ quartile are classified as having 'High Prior Level.' For simplicity, participants in the $2^{\text {nd }}$ and $3^{\text {rd }}$ quartiles are excluded from the diagrams. All three cases show that low- and highlevel participants benefit from the program such that additional amounts of treatment (e.g., more modules) result in higher post levels of ability $(\beta>0)$. Also, the lines do not cross signifying that prior levels of ability are positively correlated with post levels $(\gamma>0)$. Scenario I $(\beta>0, \gamma>0$,

\footnotetext{
${ }^{* *}$ Recall that the five specific behaviors are measured using a categorical variable. For this reason, we estimated both OLS and ordered probit models for each financial behavior. Estimations from the OLS models are reported in this paper for easy comparison and interpretation. The ordered probit results are comparable to the OLS findings and are available upon request.
} 
$\lambda>0$ ) represents the case where the marginal effect of an additional module is greater for those with higher prior levels of ability than those with lower prior levels. In Scenario II ( $\beta>0, \gamma>0$, $\lambda=0$ ), both groups benefit the same from an additional module regardless of their ability level.

Finally, Scenario III $(\beta>0, \gamma>0, \lambda<0)$ represents the case where the marginal effect of an additional module is smaller for those with higher prior levels and greater for those with lower prior levels. We take this analysis into consideration when we examine the data and interpret the findings. If our program of interest has been successful at reaching financially disadvantaged consumers, which is who it was originally designed for, then ideally we would want to have Scenario III.

\section{Findings}

Table 3 presents the OLS regression results for participants' post-levels of financial ability. Six models were estimated. The dependent variable for the first model is participants' average financial ability following the program; the dependent variable for the remaining models is participants' post-level ranking of financial ability for the five financial behaviors.

The coefficients for PriorLevel and Modules are consistent with the previous literature and are positive for all of the models. They also are highly significant $(\mathrm{p}<0.01)$ for all of the financial behaviors, except the consumer complaint behavior. The findings suggest that, the higher an individual's financial ability prior to the program and the more modules they complete, the higher their financial ability will be after the program. Participation in additional modules does not appear to significantly affect a participant's consumer complaint behavior. Plausible explanations might be that the program was not as effective at improving consumer complaint 
behavior, or it was difficult to observe a significant impact for this behavior given that the program spanned a short period of time (i.e., a few days or a few weeks).

Holding constant an individual's prior financial ability and the number of modules completed, the coefficient $(\lambda)$ on the interaction term (PriorLevel*Modules) reveals that the program effect varied by a participant's prior level of financial ability. With respect to model (1), participants, who on average, had lower financial ability prior to the program gained significantly more from the program than those who already had a higher level of financial ability (see Table 3, column 1). This finding was also true for three of the five financial behaviors including 'do not run out of money,' 'pay bills on time,' and 'compare price and quality before buying' (see columns 2, 4, and 6). For the other two financial behaviors, 'talk about money with family' and 'complain when having consumer problems,' the program's impact was still higher for lower-ability consumers (negative coefficient), but the difference was statistically insignificant (see columns 3, and 5). Again, it might be that the program was ineffective at increasing the financial ability of disadvantaged consumers with respect to these two behaviors, or the two behaviors may have been difficult to change during the short span of the program, especially for participants with low prior levels.

Figure 2 presents a series of scatter plots by quartiles that were based on participants' prior levels of ability. Each one plots the actual values of participants' average post levels of ability and shows how these are related to the number of modules completed. The fitted line on each scatter plot represents the predicted values of the average post levels based on the regression results. Note that the slope of the fitted lines for the $1^{\text {st }}$ and $2^{\text {nd }}$ quartiles are steeper than those for the $3^{\text {rd }}$ and $4^{\text {th }}$ quartiles, which resembles scenario III in Figure 1 . The 
interpretation is that we observe a greater positive impact of the program for those in the lower quartiles (i.e., those with lower levels of ability prior to the program).

One might question why the fitted lines in the $2^{\text {nd }}$ and $4^{\text {th }}$ quartiles are more non-linear and less smooth than those in the $1^{\text {st }}$ and $3^{\text {rd }}$ quartiles. There are at least two possible reasons. First, it might be that the number of modules is somehow related to which modules are taught such that certain modules matter more than others for those in the upper quartiles (i.e., those with greater levels of prior ability). For those in the $1^{\text {st }}$ quartile (i.e., those with low prior levels), the number of lessons appears to have a fairly linear effect such that each model tends to have the same impact on post levels no matter which module is taught. Another possible reason for the inconsistency in linearity across quartiles is that this could be an artifact of the data. It could simply be that we have more observations in the $1^{\text {st }}$ and $3^{\text {rd }}$ quartiles than in the $2^{\text {nd }}$ and $4^{\text {th }}$ quartiles, and the line gets smoother the more observations we have. See Table 2 for the number of observations in each quartile $\left(1^{\text {st }}\right.$ quartile: $n=188 ; 2^{\text {nd }}$ quartile: $n=74 ; 3^{\text {rd }}$ quartile: $n=186 ; 4^{\text {th }}$ quartile: $\mathrm{n}=91)$.

With respect to the demographic variables in Table 3, we find that post-level financial ability is also determined by the participant's age, gender, schooling, household size, and personal income. Holding the number of modules and prior level constant, older participants, females, those with more schooling, and those with larger families show significantly higher levels of financial ability after the program. Income appears to be a significant predictor as well, but no consistent pattern is observed. We also find that a participant's post level of ability depends on whether the participant is an agent or a client. Specifically, after all other characteristics are controlled for, being a client is associated with achieving significantly higher outcomes after the program. This may be due to the fact that participants who are clients have 
stronger motivation to learn and change their own financial behaviors, whereas participants who are agents are primarily attending the program to become familiar with the material so that they can teach it to their clients. However, as previously noted, we found quantitative and qualitative evidence from additional analysis not presented in this paper, that a significant number of the agents were struggling financially themselves and that the financial behaviors of the agents and clients were not all that different from each other.

\section{Discussion: Do Financially Disadvantaged Consumers Learn As Much?}

This paper used data collected from a retrospective pre-test to investigate the impact that a financial education program has on the consumer finance behaviors of the participants. More specifically, we compared the program's impact across participants with varying levels of financial competency prior to the program and examined whether the program was meeting the educational needs of those it was originally designed to target - namely, financially disadvantaged consumers. While most studies have concentrated on whether or not a program improves financial behaviors, this study investigated how the magnitude of the change depends on a participant's initial level of financial ability. The findings show that this particular financial education program not only significantly improved participants' financial behaviors on average, but it also had a particularly strong impact on the financial behaviors of participants who reported lower levels of financial ability at the onset of the program. This result is quite remarkable considering that we also found that low levels of prior ability were strongly associated with lower outcomes at the completion of the program. That is, despite the fact that lower-ability consumers may have remained at relatively low levels of financial competency after the program, the greatest improvement in behavior was observed for those with lower prior abilities for the majority of financial behaviors that were examined in this study. 
What likely contributed to this finding? First, it may have been that the curriculum materials were well-matched to the target population and effectively met the financial needs of consumers with low levels of financial competency while still providing valuable information to those with higher levels of competency. It may also have been that participants who had more limited financial ability at the onset of the program had stronger motivation to learn from the program than those who already had more moderate to advanced levels of ability. The literature has shown that motivation and willingness to learn are crucial to student learning (Hicks 2005; Reis, Colbert, \& Hebert 2005).

The findings have important implications for consumer educators, program developers, and financial counselors and planners. In particular, we learned that taking into account a participant's prior levels of ability is critical when designing and delivering a program or counseling session. Also, we found that the amount of education received and the content of that education may need to be tailored according to participants’ varying levels of financial ability. ${ }^{\dagger \dagger}$ The bottom line is that there is not likely to be a "one-size-fits-all" financial education program for consumers, which is consistent with the results of other recent studies (e.g., Lyons \& Scherpf 2004; Lyons, Chang, \& Scherpf 2007). Identifying the financial needs of target populations and improving the "match" of programs and curricula to these populations may help to increase teaching effectiveness across programs, and ultimately, to reduce disparities in financial ability across consumers.

From a practical standpoint, educators and counselors can take stock of their existing financial education resources and services and evaluate whether they are successfully targeting those who they were designed to target. They can then look for opportunities to enhance their

\footnotetext{
${ }^{\dagger \dagger}$ Recall, for instance, the inconsistencies in the impact of various modules for participants in the higher quartiles in Figure 2.
} 
existing efforts by focusing on improving consumer finance areas where the target population is found to be weakest and the areas where more immediate behavior change is possible. This will help to better "match" the curriculum materials to students/clients. Educators and counselors may also want to take into consideration how technology and delivery format can affect some groups' access to the information and also their ability to process the information given their level of financial competency. Students/clients can also be made aware of other existing and credible resources that have been designed to meet the financial needs of specific target populations (e.g., financially disadvantaged consumers). Finally, consumer educators, and especially financial counselors, may want to think about developing better intake forms for their students/clients that not only identify the financial resources and services they need, but also whether these resources and services match their level of financial competency. These forms can be administered as an evaluation or assessment prior to the program or counseling session.

With this said, one needs to be somewhat cautious when interpreting the findings of this study, especially given the limitations of the data. First, we did not have non-participant data. The treatment effect measured in this paper was the effect of the number of modules completed conditional on some level of participation, instead of looking at those who participated in the program versus those who did not. Yet, a significant amount of insight was gained from this study about the role that participants' prior levels of ability can play with respect to curriculum design and teaching effectiveness, especially since the sample had substantial variation with respect to the number of modules completed. Second, the data we used were taken from a oneshot survey administered immediately after the program, which may not necessarily reflect the long-term impact that the program has on actual behavior change. Also, prior and post levels of financial ability were determined entirely by a participant's self-reported perceptions, which may 
not necessarily have captured an individual's actual change in behavior. However, there is evidence from the literature that immediate and self-reported changes in financial management practices may be more meaningful than looking at consumers’ long-term financial outcomes (Muske \& Winter, 2004). Nevertheless, a future follow-up evaluation to assess the program’s long-run impact could help to provide additional insight into the findings presented in this paper. 


\section{Appendix \\ Identifying Consumers with Limited Financial Ability}

It appears that consumers who live with other adult members in the household have significantly higher levels of prior financial ability than those who do not have an adult living in the household. On the other hand, controlling for the presence of other adult members, we find that household size is negatively associated with prior levels of ability. Taking these two findings into consideration, we speculate that consumers with low levels of financial competency are more likely to be single and also more likely to have children, suggesting that single parents are at greater risk for facing financial challenges. At the same time, due to certain human capital attributes that are not completely explained by education and income, those with higher financial ability may be married and tend to have fewer children.

Income is also highly correlated with initial levels of financial ability. Compared to those who have a monthly income of $\$ 1,000-1,500$, participants who earn more than $\$ 1,500$ per month are significantly more capable of handling their finances. Controlling for the presence of another adult member in the household, we find that income from another adult member, or another source, does not significantly affect a participant's level of financial ability. However, those who participated in the program in the Chicago metropolitan area have significantly lower financial abilities on average than those who participated in the program outside of the Chicago area. Not surprisingly, even after controlling for income, education, and other demographic characteristics, we find that clients are significantly more likely to start off with lower financial ability than agents. It is particularly surprising that clients demonstrate higher financial ability than agents after completing the program (see Table 3). Note that formal schooling does not appear to significantly affect participants' prior financial ability.

Table A1: Determinants of Average Prior Level of Financial Ability

\begin{tabular}{|c|c|c|c|}
\hline & Coeff & S.E. & \\
\hline Age & -0.001 & $(0.002)$ & \\
\hline Female (\%) & -0.065 & $(0.057)$ & \\
\hline Years of schooling & 0.010 & $(0.010)$ & \\
\hline Household size & -0.061 & $(0.014)$ & $* * *$ \\
\hline Household has other adult member (\%) & 0.198 & $(0.052)$ & $* * *$ \\
\hline \multicolumn{4}{|l|}{ Personal monthly income } \\
\hline$<\$ 250(\%)$ & -0.153 & $(0.114)$ & \\
\hline$\$ 250-\$ 499(\%)$ & -0.148 & $(0.097)$ & \\
\hline$\$ 500-\$ 749(\%)$ & -0.016 & $(0.084)$ & \\
\hline$\$ 750$ - \$999 (\%) & -0.085 & $(0.076)$ & \\
\hline$\$ 1000$ - \$1249 (\%) & -0.135 & $(0.063)$ & $* *$ \\
\hline$\$ 1250$ - \$1499 (\%) & -0.187 & $(0.057)$ & $* * *$ \\
\hline$>\$ 1500(\%)$ & (omitted) & & \\
\hline Household has other income sources (\%) & 0.034 & $(0.045)$ & \\
\hline Chicago metropolitan area (\%) & -0.121 & $(0.041)$ & $* * *$ \\
\hline Participant is a client (\%) & -0.195 & $(0.083)$ & $* *$ \\
\hline Number of modules completed & -0.006 & $(0.014)$ & \\
\hline Constant & 2.061 & $(0.230)$ & $* * *$ \\
\hline Number of Observations & 578 & & \\
\hline Adjusted R-Sqr & .1680 & & \\
\hline Root MSE & .4506 & & \\
\hline
\end{tabular}

Notes: The dependent variable is measured as a continuous variable ranging from 1 to 4 and represents a participant's prior level of financial ability averaged over five financial behaviors. OLS coefficients and standard errors are reported. ${ }^{* * *} \mathrm{p}<.01,{ }^{* *} \mathrm{p}<.05,{ }^{*} \mathrm{p}<.10$ 


\section{References}

Anderson, S. G., Zhan, M., \& Scott, J. (2004). Targeting financial management training at lowincome audiences. Journal of Consumer Affairs, 38 (1), 167-177.

Bird, E. J., Hagstrom, P. A., \& Wild, R. (1999). Credit card debts of the poor: High and rising. Journal of Policy Analysis and Management, 18 (4), 125-133.

Block-Lieb, S., Baron-Donovan, C., Gross, K., \& Wiener, R. (2004). Survey: The coalition for consumer bankruptcy debtor education: A report on its pilot program. Emory Bankruptcy Developments Journal, 21, 233-258. Retrieved November 28, 2005 from http://www.nyls.edu/pdfs/emory.pdf.

Braunstein, S. \& Welch, C. (2002). Financial literacy: An overview of practice, research, and policy. Federal Reserve Bulletin, November, 445-457.

Casanova, P.F., Garcia-Linares, M.C., de la Torre, M.J., \& Carpio, M. de la V. (2005). Influence of family and socio-demographic variables on students with low academic achievement. Educational Psychology, 25 (4), 423-435.

Hicks, T. (2005). Assessing the academic, personal and social experiences of pre-college students. Journal of College Admission, 186, 19-24.

Jariah, M., Husniyah, A. R., Laily, P., \& Britt, S. (2004). Financial behavior and problems among university students: Need for financial education. Journal of Personal Finance, 3 (1), 82-96.

Lamb, T. (2005). The retrospective pretest: An imperfect but useful tool. The Evaluation Exchange, XI (2), 18. Retrieved October 1, 2005 from http://www.gse.harvard.edu/hfrp/eval/archives.html. 
Lamb, T. A. \& Tschillard, R. (2005). Evaluating learning in professional development workshops: Using the retrospective pretest. Journal of Research in Professional Learning. Retrieved November 24, 2005 from http://www.nsdc.org/library/publications/research/index.cfm.

Lyons, A. C. (2005). Financial education and program evaluation: Challenges and potentials for financial professionals. Journal of Personal Finance, 4 (4), 56-68.

Lyons, A. C., Chang, Y., \& Scherpf, E. (2007). Translating financial education into behavior change for low-income populations. Financial Counseling and Planning Journal, 17 (2), forthcoming.

Lyons, A. C., Palmer, L., Jayaratne, K. S. U., \& Scherpf, E. (2006). Are we making the grade? A national overview of financial education and program evaluation. The Journal of Consumer Affairs, 40 (2), 208-235.

Lyons, A. C. \& Scherpf, E. (2004). Moving from unbanked to banked: evidence from the money smart program. Financial Services Review, 13 (3), 215-231.

Marlowe, J., Godwin, D. D., \& Maddux, E. (1996). Effects of an educational program on financial knowledge and behavior of welfare recipients. Journal of Consumer Education, $14,1-7$.

Meyer, J. H. F. \& Shanahan, M. P (1999). Modeling learning outcomes in first-year economics. Paper presented at $8^{\text {th }}$ European Conference for Research on Learning and Instruction, Gotenborg, Sweden.

Meyer, J. H. F. \& Shanahan, M. P. (2001). Making teaching responsive to variation in student learning. In C. Rust (ed.) Improving Student Learning 8: Improving Student Learning Strategically, Oxford: OCSD/Oxford Brookes University. 
Muske, G. \& Winter, M. (2004). Personal financial management education: An alternative paradigm. Financial Counseling and Planning, 15 (2), 79-88.

O’Neill, B. \& Xiao, J. J. (2003). Financial fitness quiz: A tool for analyzing financial behavior. Consumer Interests Annual, 49, Retrieved November 1, 2005 from http://www.consumerinterests.org/files/public/FinancialFitnessQuiz_03.pdf.

Petrides, K. V., Chamorro-Premuzic, T., Frederickson, N., \& Furnham, A. (2005). Explaining individual differences in scholastic behaviour and achievement. British Journal of Educational Psychology, 75 (2), 239-255.

Reis, S. M., Colbert, R. D, \& Hebert, T. P. (2005). Understanding resilience in diverse, talented students in an urban high school. Roeper Review, 27 (2), 110-120.

Shanahan, M. P. \& Meyer, J. H. F. (2003). Measuring and responding to variation in aspects of students’ economic conceptions and learning engagement in economics. International Review of Economics Education, 1 (1), 9-35.

Xiao, J. J., Newman, B. M., Prochaska, J. M., Leon, B. \& Bassett, R. L. (2004). Voices of debt troubled consumers: A theory-based qualitative inquiry. Journal of Personal Finance, 3 (2), 56-74.

Zietz, J. \& Joshi, P. (2005). Academic choice behavior of high school students: economic rationale and empirical evidence. Economics of Education Review, 24 (3), 297-308. 


\section{Figure 1}

Program Impact Scenarios by Participants' Prior Levels of Financial Ability

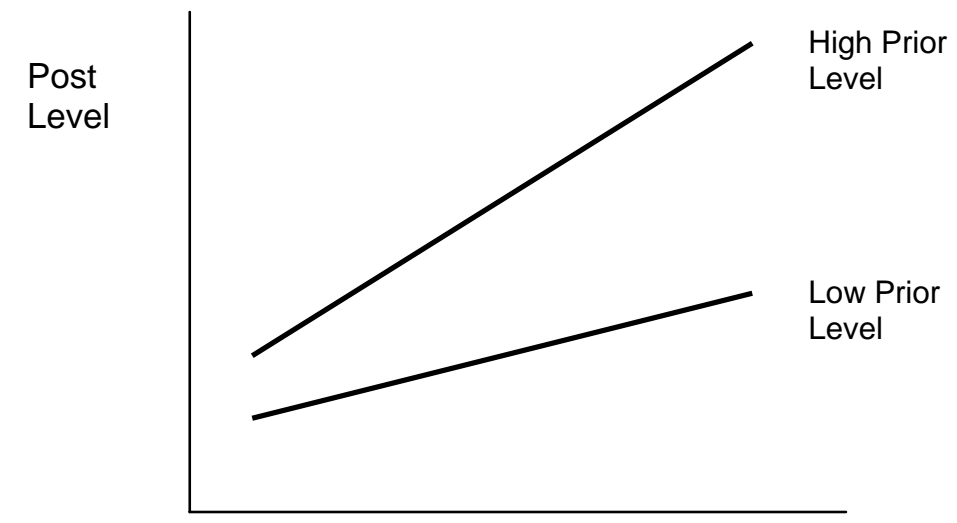

Amount of Treatment

Scenario I: $\beta>0, \gamma>0, \lambda>0$

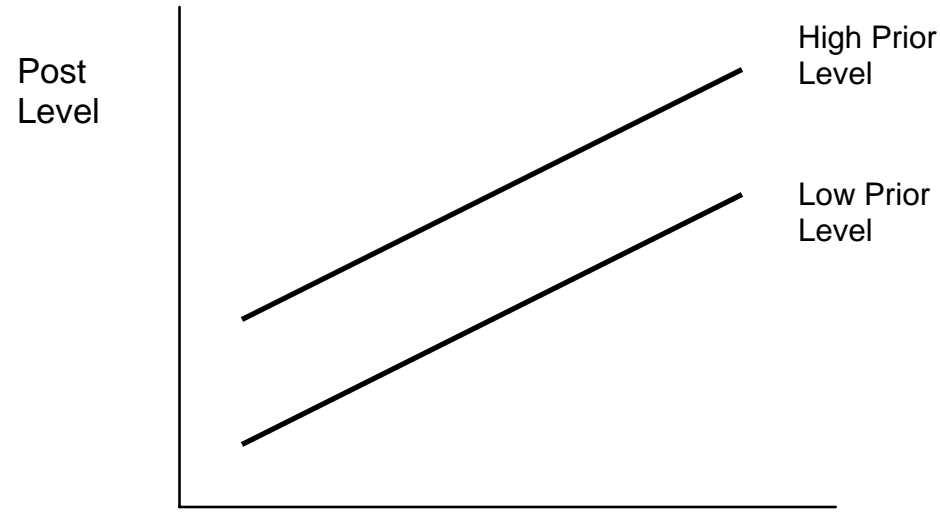

Amount of Treatment Scenario II: $\beta>0, \gamma>0, \lambda=0$

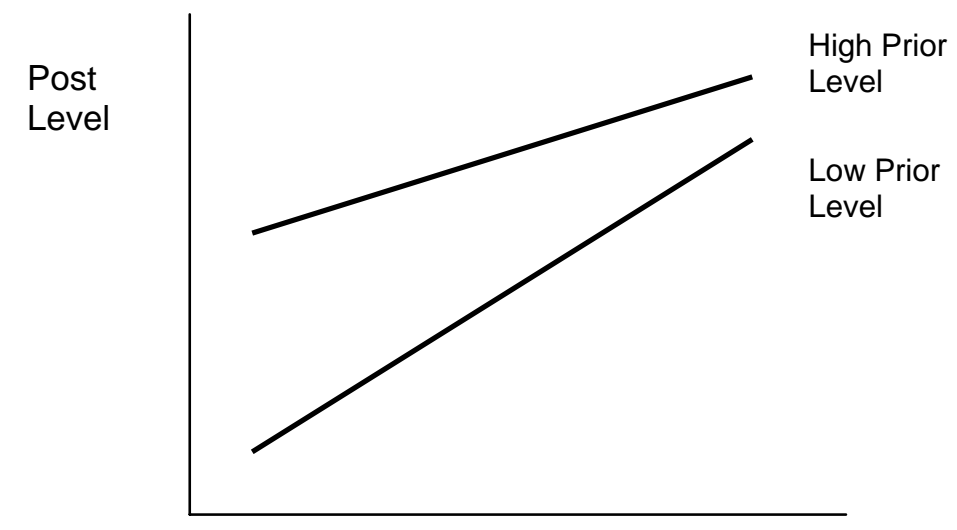

Scenario III: $\beta>0, \gamma>0, \lambda<0$ 
Figure 2

Fitted Lines for Average Post Levels of Ability: By Quartiles Based on Participants' Prior Levels of Ability

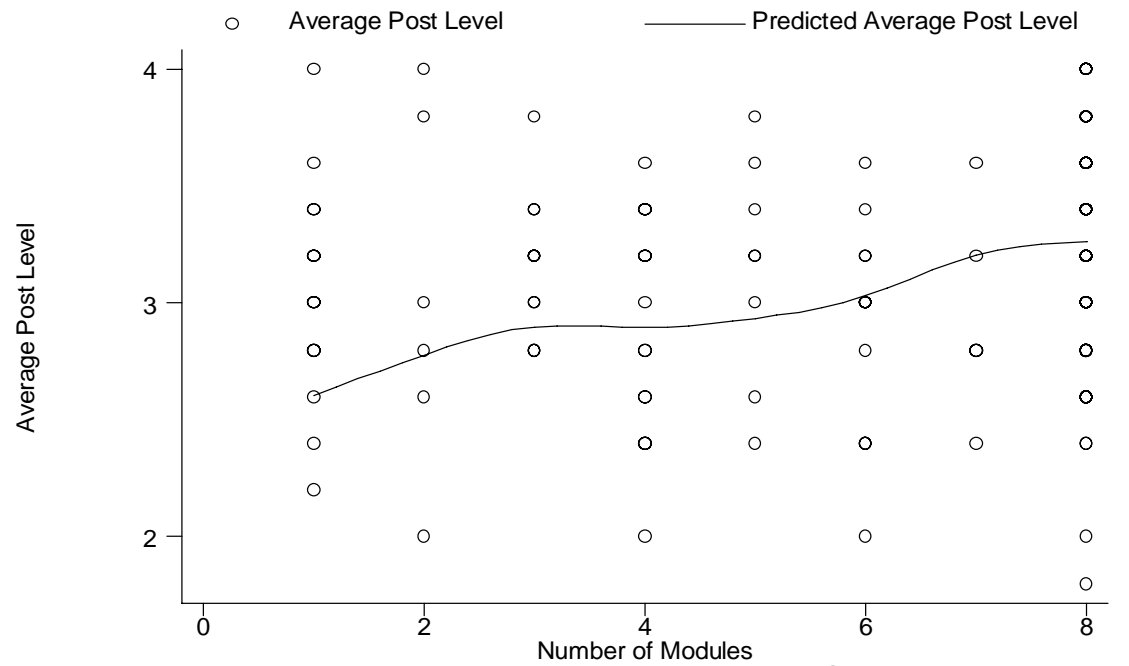

Fitted Values, Average Prior Level First Quartile

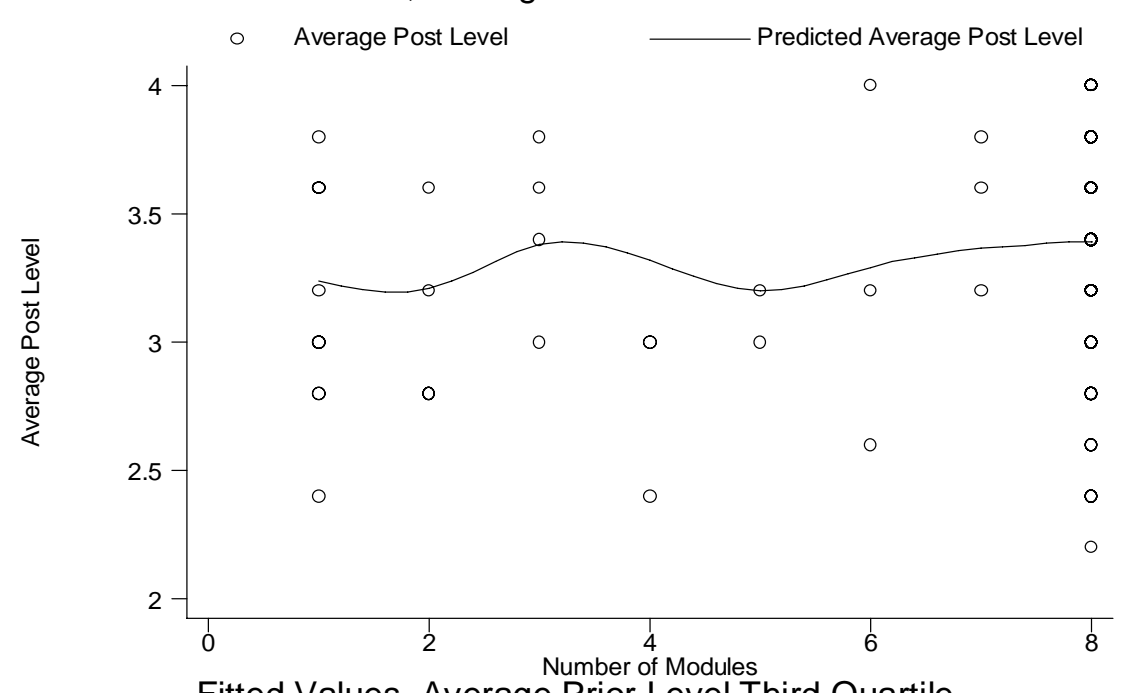

Fitted Values, Average Prior Level Third Quartile

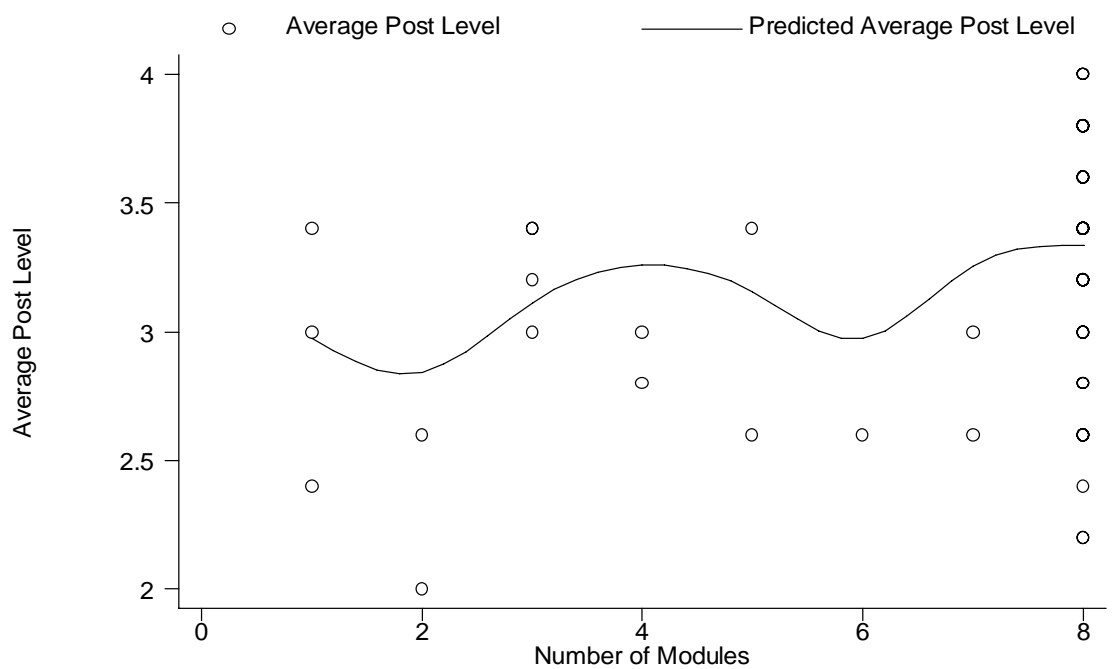

Fitted Values, Average Prior Level Second Quartile

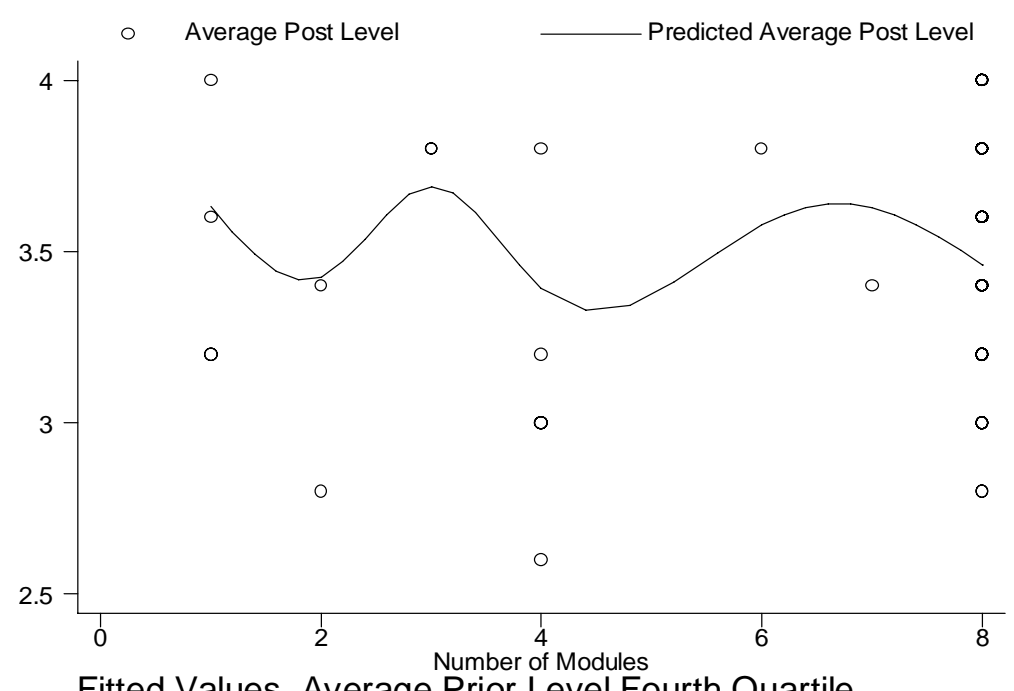

Fitted Values, Average Prior Level Fourth Quartile 


\section{Table 1}

Sample Characteristics $(\mathrm{N}=602)$

\begin{tabular}{lrr}
\hline & Mean (or \%) & S.D. \\
\hline Age & 39.01 & 11.38 \\
Female (\%) & 87.04 & 33.61 \\
Years of schooling & 14.57 & 2.40 \\
Household size & 3.21 & 1.55 \\
Household has other adult member (\%) & 70.27 & 45.75 \\
Personal monthly income & & \\
$\quad$ \$250 (\%) & 3.49 & 18.36 \\
\$250 - \$499 (\%) & 5.81 & 23.42 \\
$\$ 500-\$ 749(\%)$ & 7.64 & 26.59 \\
$\$ 750$ - \$999 (\%) & 8.14 & 27.37 \\
\$1000 - \$1249 (\%) & 12.46 & 33.05 \\
$\quad$ \$1250 - \$1499 (\%) & 15.12 & 35.85 \\
$>$ \$1500 (\%) & 47.34 & 49.97 \\
Household has other income sources (\%) & 45.35 & 49.82 \\
Chicago metropolitan area (\%) & 60.63 & 48.90 \\
Participant is a client (\%) & 27.74 & 44.81 \\
Number of modules completed & 6.72 & 2.31 \\
& & \\
Overall Prior Level (N=578) & 1.83 & 0.49 \\
Overall Outcome (N=545) & 3.29 & 0.44
\end{tabular}

Notes: Based on survey respondents who participated in the All My Money program between 1998-2002.

Table 2

A Comparison of Pre and Post Differentials by Prior Level of Financial Ability

\begin{tabular}{|c|c|c|c|c|c|c|c|}
\hline & \multirow[b]{2}{*}{$\mathrm{N}^{\mathrm{b}}$} & \multicolumn{2}{|c|}{ Prior Level } & \multicolumn{2}{|c|}{ Post Level } & \multirow[t]{2}{*}{$|t|$} & \\
\hline & & Mean & S.D. & Mean & S.D. & & \\
\hline $1^{\text {st }}$ Quartile $^{\mathrm{a}}$ & 188 & 1.31 & 0.32 & 3.15 & 0.47 & 47.86 & $* * *$ \\
\hline $2^{\text {nd }}$ Quartile & 74 & 1.80 & 0.00 & 3.21 & 0.48 & 25.45 & $* * *$ \\
\hline $3^{\text {rd }}$ Quartile & 186 & 2.08 & 0.10 & 3.36 & 0.40 & 44.46 & $* * *$ \\
\hline $4^{\text {th }}$ Quartile & 91 & 2.52 & 0.14 & 3.49 & 0.33 & 27.22 & $* * *$ \\
\hline
\end{tabular}

Notes: $* * * \mathrm{p}<.01$ by paired $\mathrm{t}$-tests.

a Quartiles were determined by participants' prior levels of financial ability.

${ }^{\mathrm{b}}$ The number of observations varies across quartiles due to the fact that several observations had the same values at the cutoff points for the quartiles. 
Table 3

OLS Regressions for Post-Level Financial Ability

\begin{tabular}{|c|c|c|c|c|c|c|}
\hline & $\begin{array}{c}\text { (1) } \\
\text { Average } \\
\text { Post-Level } \\
\text { Ability }^{\mathrm{a}}\end{array}$ & $\begin{array}{c}\text { (2) } \\
\text { Do not run out } \\
\text { of money }\end{array}$ & $\begin{array}{c}(3) \\
\text { Talk about } \\
\text { money with } \\
\text { family }\end{array}$ & $\begin{array}{l}\text { (4) } \\
\text { Pay bills on } \\
\text { time }\end{array}$ & $\begin{array}{c}(5) \\
\text { Complain } \\
\text { when having } \\
\text { consumer } \\
\text { problems }\end{array}$ & $\begin{array}{c}(6) \\
\text { Compare price } \\
\text { and quality } \\
\text { before buying }\end{array}$ \\
\hline & coeff se & coeff se & coeff se & coeff se & coeff se & coeff se \\
\hline Prior level $^{\mathrm{b}}$ & $0.756(0.083)^{* * *}$ & $0.613(0.064)^{* * *}$ & $0.590(0.086)^{* * *}$ & $0.572(0.060)^{* * *}$ & $0.505(0.104)^{* * *}$ & $0.627(0.068)^{* * *}$ \\
\hline Number of modules completed & $0.174(0.023)^{* * *}$ & $0.169(0.027)^{* * *}$ & $0.089(0.034)^{* * *}$ & $0.180(0.028)^{* * *}$ & $0.063(0.039)$ & $0.160(0.032){ }^{* * *}$ \\
\hline Prior level $\times$ Number of modules & $-0.070(0.013)^{* * *}$ & $-0.036(0.009)^{* * *}$ & $-0.011(0.013)$ & $-0.043(0.009)^{* * *}$ & $-0.007(0.015)$ & $-0.031(0.010)^{* * *}$ \\
\hline Age & $0.008(0.002)^{* * *}$ & $0.005(0.002)^{* *}$ & $0.003(0.003)$ & $0.007(0.002)^{* * *}$ & $0.010(0.003)^{* * *}$ & $0.005(0.003) *$ \\
\hline Female (\%) & $0.224(0.057)^{* * *}$ & $0.124(0.072)^{*}$ & $0.168(0.097)^{*}$ & $0.194(0.075)^{* *}$ & $0.212(0.114)^{*}$ & $0.064(0.081)$ \\
\hline Years of schooling & $0.056(0.008)^{* * *}$ & $0.052(0.011)^{* * *}$ & $0.031(0.013)^{* *}$ & $0.065(0.010)^{* * *}$ & $0.048(0.015)^{* * *}$ & $0.045(0.012)^{* * *}$ \\
\hline Household size & $0.035(0.014)^{* *}$ & $0.047(0.018)^{* *}$ & $0.077(0.024)^{* * *}$ & $0.021(0.019)$ & $-0.032(0.028)$ & $0.032(0.021)$ \\
\hline Household has other adult member (\%) & $0.024(0.054)$ & $-0.128(0.068)^{*}$ & $0.089(0.090)$ & $0.012(0.070)$ & $0.141(0.104)$ & $0.007(0.075)$ \\
\hline \multicolumn{7}{|l|}{ Personal monthly income } \\
\hline$<\$ 250(\%)$ & $0.094(0.124)$ & $0.289(0.152)^{*}$ & $0.190(0.201)$ & $0.362(0.162)^{* *}$ & $-0.054(0.244)$ & $-0.126(0.177)$ \\
\hline$\$ 250-\$ 499(\%)$ & $0.012(0.100)$ & $-0.024(0.125)$ & $0.032(0.169)$ & $-0.005(0.133)$ & $0.022(0.196)$ & $-0.168(0.141)$ \\
\hline$\$ 500-\$ 749(\%)$ & $-0.014(0.088)$ & $-0.268(0.110)^{* *}$ & $-0.102(0.144)$ & $0.031(0.116)$ & $0.088(0.170)$ & $0.001(0.124)$ \\
\hline$\$ 750$ - \$999 (\%) & $0.097(0.078)$ & $0.268(0.098)^{* * *}$ & $0.027(0.129)$ & $0.113(0.103)$ & $0.012(0.153)$ & $0.221(0.111)^{* *}$ \\
\hline$\$ 1000-\$ 1249(\%)$ & $0.138(0.064)^{* *}$ & $0.144(0.082)^{*}$ & $0.014(0.108)$ & $0.104(0.083)$ & $0.080(0.126)$ & $0.154(0.091) *$ \\
\hline$\$ 1250$ - \$1499 (\%) & $0.086(0.058)$ & $0.069(0.073)$ & $0.013(0.097)$ & $0.089(0.076)$ & $0.053(0.113)$ & $0.243(0.082)^{* * *}$ \\
\hline$>\$ 1500(\%)$ & --- & ---- - & ---- & ---- & ---- & ---- - n \\
\hline Household has other income sources (\%) & $0.065(0.046)$ & $0.081(0.058)$ & $0.070(0.077)$ & $0.039(0.060)$ & $0.091(0.090)$ & $0.077(0.065)$ \\
\hline Chicago metropolitan area (\%) & $0.041(0.043)$ & $0.128(0.054)^{* *}$ & $-0.042(0.071)$ & $0.016(0.056)$ & $0.029(0.083)$ & $0.025(0.060)$ \\
\hline Participant is a client (\%) & $0.189(0.078)^{* *}$ & $0.422(0.097)^{* * *}$ & $0.228(0.125)^{*}$ & $0.276(0.105)^{* * *}$ & $-0.214(0.149)$ & $0.354(0.109)^{* * *}$ \\
\hline $\mathrm{N}$ & 539 & 560 & 566 & 562 & 564 & 566 \\
\hline Adj R-sqr & 0.9820 & 0.9756 & 0.9360 & 0.9746 & 0.9059 & 0.9680 \\
\hline Root MSE & 0.4453 & 0.5770 & 0.7651 & 0.5996 & 0.8920 & 0.6453 \\
\hline
\end{tabular}

\footnotetext{
a The dependent variable for column (1) is defined as a participant's post level of financial ability averaged over the five financial behaviors, which is a continuous variable ranging from 1 to 4 . The dependent variable for columns (2)-(6) is defined as a participant's rating of their post level ability for each of the respective financial behaviors. For the latter five columns, the dependent variable is measured by categorical responses that equal 1 , 2 , 3 , or 4 . For all of the models, the coefficients and standard errors from the OLS regressions are reported for ease of comparison and interpretation. Ordered probit coefficients for columns (2)-(6) yield comparable results and are available upon request. b The variable "Prior level” is also defined differently for column (1) versus columns (2)-(6). For (1), "Prior level” refers to a participant's prior level of financial ability averaged over the five financial behaviors. For (2)-(6), it is a participant's ranking of their prior level of financial ability for each respective financial behavior. ${ }^{* * *} \mathrm{p}<.01,{ }^{* *} \mathrm{p}<.05,{ }^{*} \mathrm{p}<.10$
} 